\title{
Industrial perspective on deep brain stimulation: history, current state, and future developments
}

\section{Ali Sarem-Aslani * and Keith Mullett}

Medtronic International Trading Sàrl, Tolochenaz, Switzerland

Edited by:

Thomas E. Schlaepfer, University

Hospital of Bonn, Germany

\section{Reviewed by:}

Ziad Nahas, Medical University of South Carolina, US Minor Outlying Islands

Sidney Kennedy, University Health Network, Canada

\section{*Correspondence:}

Ali Sarem-Aslani, Medtronic Europe, Earl-Bakken-Platz 1, 40670

Meerbusch, Germany.

e-mail: ali.sarem.aslani@medtronic. com

\begin{abstract}
Deep brain stimulation (DBS) emerged in the late 1960s as a possible therapeutic alternative to lesioning in patients with severe, chronic, intractable pain. DBS devices in the era were based on cardiac pacing technology but were greatly modified in implementation due to the unique needs of DBS. Clinical studies in the 1970s and early 1980s have revealed a technique with modest results which did not lead to regulatory approval for the treatment of pain. In the 1980s a new application for DBS emerged in the treatment of movement disorders. Clinical trials confirmed the robustness of the therapy leading to approvals by regulatory authorities in the US and Europe for the treatment of tremor and the symptoms of Parkinson's disease. Technology based on that used for earlier clinical research in pain was improved by leveraging advances in cardiac pacing technology resulting in the sophisticated and reliable systems available today. In the 1990s scientific exploration began in the treatment of psychiatric disorders which is ongoing today. Simultaneously, studies into the treatment of epilepsy were begun which resulted in regulatory approval in Europe. Suggestions have been made to expand these scientific explorations to other central nervous system dysfunctions. Opportunity remains to improve the technology including individualized and symptom specific stimulation patterns, more physician and patient friendly programming, and possibly closed-loop systems for more situation dependent and effective therapy.
\end{abstract}

Keywords: deep brain stimulation, history, technology, pain, movement disorders, psychiatric disorders, epilepsy

\section{INTRODUCTION}

Neurostimulation is a method applied to treat various neurological disorders including chronic pain, urinary incontinence, and movement disorders. The vast experience with active implantable technology in cardiac stimulation has been evolved successfully into the development of neurostimulators and applications for chronic neurological and gastro-urological diseases. Major developments have been achieved through ongoing collaboration and partnership between academia and medical device industry. More than 80,000 patients have been treated with DBS worldwide through the end of 2010. The aim of this article is to provide an overview of the history, present status, and potential future developments of deep brain stimulation (DBS).

\section{NOTICE}

This article discusses current developments and future possibilities for DBS therapies. Three companies, Medtronic, Inc. (Minneapolis, MN, USA), St Jude Medical (St. Paul, MN, USA), and Boston Scientific (Natick, MA, USA) have developed DBS systems currently at various stages of regulatory evaluation and approval. The authors wish to emphasize that the only Medtronic DBS systems approved by regulatory authorities in Europe and the US are for the following therapies:

- Essential Tremor: CE Mark; FDA approval

- Symptoms of Parkinson's Disease (PD): CE Mark; FDA approval
- Dystonia: CE Mark; Humanitarian Device Exemption (HDE) in US

- Obsessive Compulsive Disorder (OCD): CE Mark; HDE in US - Epilepsy: CE Mark

Refer to the product labeling packaged with Medtronic DBS products for specific indications, contraindications, warnings, precautions, adverse events summary, and patient selection. Refer to the product labeling of St Jude Medical and Boston Scientific for the specific regulatory status of these systems.

\section{DBS HISTORY AND CURRENT STATE}

With new findings on the pathophysiology and neuroanatomy of thalamocortical-basal ganglia neural circuits in neurological and psychiatric disorders, Neurosurgeons, Neurologists, and Psychiatrists have explored DBS targets in regions that correspond to traditional lesional targets. At first, DBS was considered to be "reversible lesioning." Further investigations, however, suggested that stimulation-induced modulation of brain activities may rather be the mechanism of action (Kringelbach et al., 2007). During the evolution of DBS in the treatment of pain, movement disorders, epilepsy, and psychiatric disorders, industry has worked hand-in-hand with physicians to develop these therapies.

\section{PAIN}

The first evidence of physician/industry collaboration on DBS came in 1969 when Hosobuchi approached Medtronic, Inc. to 
design and build a system to stimulate the ventral posterior medial (VPM) nucleus of the thalamus in a patient with severe intractable facial pain (Hosobuchi et al., 1973). Today, DBS for pain is utilized in a small number of centers who report positive results in a highly selected patient population (Owen et al., 2007).

\section{MOVEMENT DISORDERS}

In 1987, Siegfried and Benabid independently reported suppression of severe, intractable tremor by stimulation of the ventral intermediate (Vim) nucleus of the thalamus (Benabid et al., 1987, 1991, 1993; Siegfried and Shulman, 1987). Although there were earlier reports of stimulation suppressing involuntary movements in the context of treating pain, these were the first reports of chronic DBS specifically for the treatment of movement disorders. Subsequently, Benabid collaborated with Medtronic on the development of DBS for treating patients with severe, intractable tremor which culminated in a multicenter clinical trial and regulatory approval for the therapy. In 1994, Siegfried reported improvement of multiple symptoms of PD by stimulation of the globus pallidus internal (GPi; Siegfried and Lippitz, 1994). In 1993, Benabid extended this work to stimulation of the sub-thalamic nucleus (STN) in patients with PD (Limousin et al., 1995). Clinical studies in North America and Europe resulted in regulatory approvals for these two indications (Limousin et al., 1999; The Deep Brain Stimulation for Parkinson's Disease Study Group, 2001). Later clinical studies confirmed the early data with evidence Level 1 results (Deuschl et al., 2006; Weaver et al., 2009; Williams et al., 2010).

Deep Brain Stimulation has been explored for treating other movement disorders, most notably dystonia with stimulation in the GPi (Coubes et al., 2000; Kupsch et al., 2006; Mueller et al., 2008; Vidailhet et al., 2009). Studies are ongoing for DBS in the treatment of cervical dystonia (Krauss et al., 1999), tardive dystonia (Trottenberg et al., 2001; Gruber et al., 2009), Gilles de la Tourette syndrome (Temel and Visser-Vandewalle, 2004; Porta et al., 2009; Hariz and Robertson, 2010), and other movement disorders.

\section{EPILEPSY}

Velasco et al. (1987) reported favorable results with stimulation of the centromedian nucleus of the thalamus with DBS. In 2002, Lozano reported seizure reduction with DBS of the anterior nucleus (AN) of the thalamus (Hodaie et al., 2002). This led to a multicenter, double blind, randomized industry sponsored clinical trial of DBS of the AN in patients with refractory epilepsy which resulted in regulatory approval for the therapy in Europe. Fisher et al. (2010) concluded that bilateral DBS of the AN is useful in medically refractory partial and secondarily generalized seizures while the complication rates are modest. However, in the US, the FDA continues to review the data for risk benefit and approval for the therapy has not yet been granted. Meanwhile, Boon conducted pilot studies of amygdalohippocampal stimulation in temporal lobe epilepsy (Vonck et al., 2002; Boon et al., 2007). These studies are ongoing. A second industry sponsored clinical study is currently underway which evaluates the effect of stimulation of the seizure focus with a device capable of either surface or depth stimulation (NeuroPace, Mountain View, CA, USA).

\section{PSYCHIATRIC DISORDERS}

In 1999, Nuttin proposed stimulation of the internal capsule (IC) as an alternative to irreversible capsulotomy in the treatment of OCD opening the gateway for exploration of DBS in psychiatric disorders (Nuttin et al., 1999). Early mixed results led to a redefinition of the target as the area just ventral to the IC (ventral capsule/ventral striatum, VC/VS) and/or the nucleus accumbens (NA; Sturm et al., 2003; Denys et al., 2010; Greenberg et al., 2010). A French multicenter study explored the effects of DBS in the associative limbic part of the STN (Mallet et al., 2008). Observations that OCD patients treated with DBS in the region of the ventral striatum showed reduced depression led teams in North America and Europe to explore the use of DBS in the treatment of severely refractory depression patients (Malone et al., 2009; Bewernick et al., 2010). Studies are ongoing in North America, Europe, and elsewhere on these applications.

Other targets for the treatment of depression disorders under clinical investigation include the white matter adjacent to Brodmann Area 25 in the subgenual cingulated cortex (Cg25; Mayberg et al., 2005; Hamani et al., 2011), the ventral caudatum (Aouizerate et al., 2009), and the lateral habenula (Sartorius et al., 2010). Very recently the lateral branch of the medial forebrain bundle has been hypothesized to represent an alternative target (Coenen et al., 2010).

Deep Brain Stimulation is currently approved for the treatment of OCD by stimulation of the VC/VS through the HDE process in the US and by CE Mark in Europe. Both approvals were based on limited data and additional studies are ongoing to further clarify the benefits and limits of the therapy. Major industry sponsored trials of DBS of the VC/VS and DBS of the Cg25 in the treatment of depression are now underway. DBS for all other applications and targets in the treatment of psychiatric disorders is at an exploratory stage. The scientific community is concerned to avoid repeating the errors of a previous era of psychosurgery by proceeding carefully and in consultation with experts in ethics (Kringelbach and Aziz, 2009).

\section{RISKS}

Infection is one the most common adverse events reported at around $2.5 \%$ per year of which about one in five results in the explant of a portion of the system. Surgical complications are reported in the $3-4 \%$ range. Intracranial hemorrhage is reported at about $3 \%$, approximately half of which are asymptomatic, a quarter are transient, and a quarter result in permanent deficit. Operative mortality is well under 1\% (Voges et al., 2007). Hardware failure including lead dislodgement and fracture can also occur leading to replacement surgery.

Depression, suicidal ideations, and suicide have been reported in patients receiving DBS for movement disorders although no direct cause and effect relationship has been established (Witt et al., 2008). Patients should be assessed preoperatively for risk and monitored post-operatively for presence of these effects.

\section{ETHICAL CONSIDERATIONS}

Other potential therapeutic applications for DBS are numerous [cluster headache, dementia, addiction, gait disorders, obesity (Halpern et al., 2008), blood pressure, etc.] The ultimate goal is 
to improve quality of life for patients and their caregivers. While there is strong evidence for DBS in Parkinson's disease, essential tremor, and dystonia, there is still more work needed to extend the knowledge on therapy efficacy, safety, and cost efficiency in other indications. Therefore it is crucial to conduct well designed controlled studies in line with the ethical criteria described by Lipsman et al. (2010). DBS should be used to help restore normal function and provide relief from distress and should never be used for augmentation or brain enhancement (Kringelbach and Aziz, 2009). The potential benefit should always be balanced with the potential risk for surgical or stimulation-induced adverse events.

\section{DESIGN AND BUILD OF DEVICES}

The components of implantable DBS systems include the neurostimulator, extensions, lead, and electrodes and the external components such as physician programmer, patient programmer (Figure 1), and a recharger for rechargeable devices.

When Hosobuchi approached Medtronic in 1969 to build a DBS system, cardiac pacing technology, the basis of the industry, utilized mercury zinc batteries housed in large devices with simple circuits. Clearly to deliver a pulse train of up to 100 pulses per second (pps) at the therapeutic voltage and pulse width required for neurostimulation demanded an alternative approach. Thus, the first DBS systems were radio frequency devices. The electrode was implanted at the appropriate brain target and cabled to a passive radio frequency receiver powered from a transmitter carried on the patient's belt. The transmitter was coupled to the implanted device with an antenna taped to the patient's skin over the implanted receiver.
Over the following two decades, improvements in power sources and circuit efficiencies in cardiac pacing were adapted for neurostimulation devices. The advent of lithium battery technology for implantable applications led to the possibility for neurostimulators to be fully implantable by the end of the 1980 s, thereby reducing the dependence on the patient to care for and manage an external device. Implantable devices are programmed by a physician programmer. The programmer communicates with the electronics of the implanted device using pulse-width and/or pulse interval-modulated encoding of an inductively coupled carrier frequency.

In addition, improvements to circuit efficiency and capability have allowed for the development of dual channel devices capable of powering two four-contact leads. A new generation of devices provides increased parameter variability thus allowing the physician to tailor the stimulation to meet the topography and nature of the patient's symptoms with the aim to optimize therapeutic outcome while minimizing side effects (Wojtecki et al., 2011). A new generation of silver vanadium oxide batteries has been developed to meet these increased power requirements.

Commercial stimulators use charge-balanced stimulation resulting in zero net flow of charge to avoid deleterious effects. Different electrode configurations can be programmed for monopolar and bipolar stimulation. Based on the specific therapy application the parameters can be adjusted over a range of $0-10.5 \mathrm{~V}$, 60-450 $\mu$ s, and 2-250 pps (Testerman et al., 2006). Typical stimulation parameters for DBS for currently approved therapies such as movement disorders are in the range of $2-4 \mathrm{~V}(2-4 \mathrm{~mA}$ for a

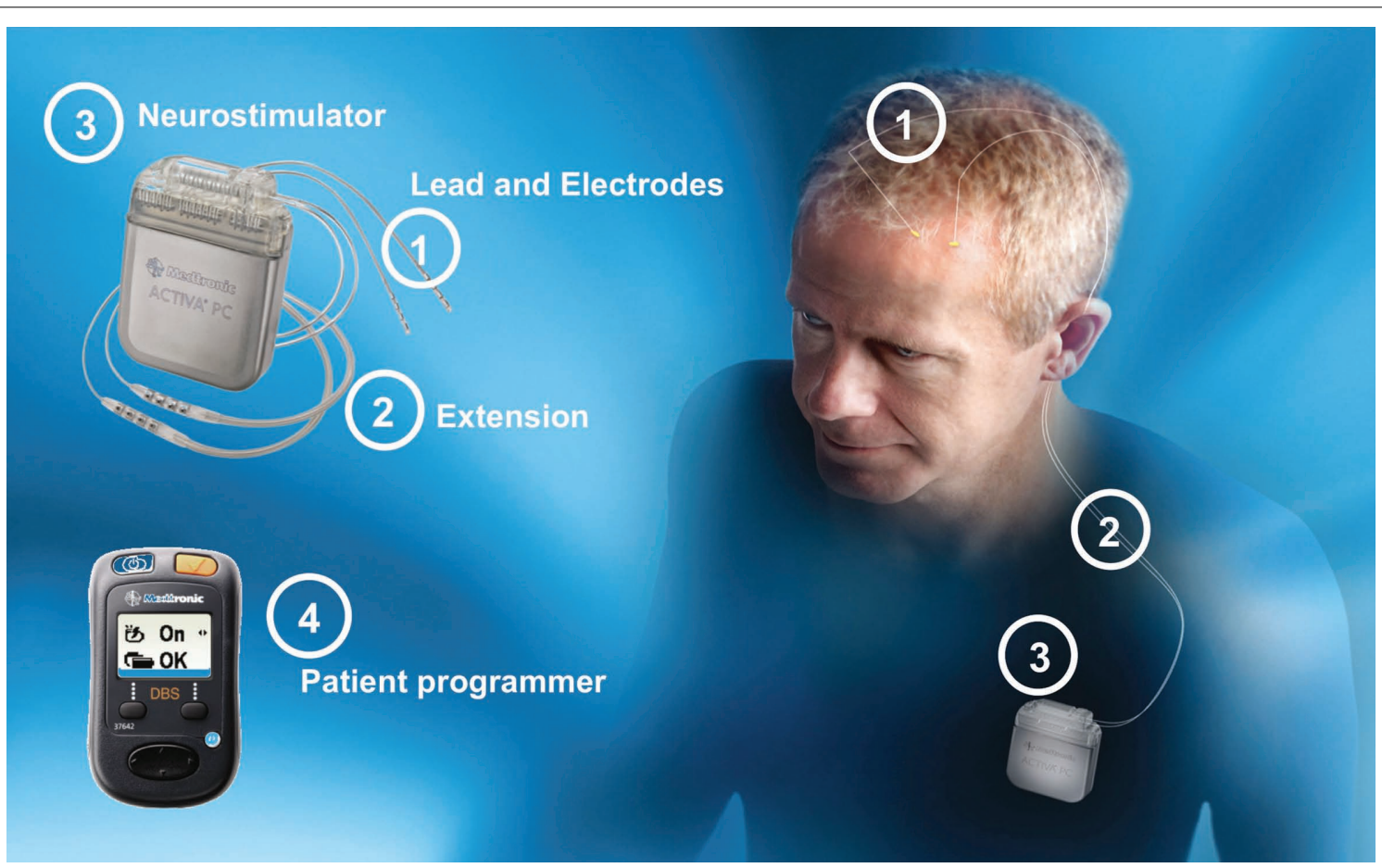

FIGURE 1 | Deep Brain Stimulator System Type Activa ${ }^{\circledR}$ PC (primary cell). The patient programmer may perform device status interrogation (e.g., power status, program group, battery status, and on/off function). 
DBS electrode impedance of $1000 \Omega$ ) 90-180 $\mu$ s pulse width, and 100-185 pps.

Due to the wide range of parameters in a neurostimulator, the battery life can vary considerably. For movement disorder applications, typical battery life expectation ranges from 2 to 5.5 years. For psychiatric applications, battery life may be considerably shorter due to the larger electrode surface areas and voltage levels required. The expected life can be from under 1 to 1.5 years although these numbers have been increasing as the targeting of the electrode contact has been refined.

The recent development of implantable rechargeable batteries has allowed physicians to provide DBS therapy to patients with higher energy requirements. Expected time-to-replacement is increased with the use of rechargeable DBS neurostimulators to 9 years. The aim of these developments is to improve patient comfort, reduce frequency of replacement surgeries, increase safety and efficacy, and to improve cost-benefit ratio of the therapy. However, recharging a neurostimulator requires patient cooperation and the patient's ability to comply should be considered before selecting this option.

Simultaneously, improvements have been made to the electrode systems. Today's electrodes are flexible, yet durable, and are configured to meet the anatomical requirements of the area to be stimulated. Pathological findings in the brains of eight Parkinson's disease patients treated with DBS showed only mild gliosis around the lead track. The authors concluded that chronic DBS does not cause damage to adjacent brain tissue (Haberler et al., 2000).

The description of the DBS implantation procedure would expand the scope of this article beyond its intent. However, it is important to point out that the surgery requires a multidisciplinary team. It involves several steps from mounting the stereotactic frame to implanting the DBS neurostimulator
(Figure 2). Recent findings from a study on Parkinson's disease patients suggest that frameless implantation of DBS leads compared to frame based technique may result in comparable clinical outcome when performed by an experienced team (Brontë-Stewart et al., 2010).

\section{FUTURE DEVELOPMENTS}

The ultimate goal of new technologies and developments is to improve patient outcome, reduce clinical burden, and reduce dependency on the patient to manage the device. Any new medical device requires the balance of three key elements: unmet medical or user need, technical feasibility (including safety and reliability), and scientific verification.

Several areas to consider are:

- The ability to steer the electrical field around the electrodes will be an advantage in optimization providing some forgiveness in electrode location while still allowing the physician to optimize the therapy post-operatively.

- Exploration of alternatives to the fixed rate pulse train may improve efficacy and/or decrease potential for adaptation over time. These alternatives could include amplitude, frequency, or pulse-width modulation and intermittent stimulation.

- Many patients with chronic neurological diseases are at a point in their life where interacting with a medical device can be confusing. Making that interaction simpler and more obvious is a continuing challenge for the industry.

- MRI safe systems will provide a great advantage to the physician in the ongoing care of these patients.

- Work will continue to explore how to identify and use biomarkers, e.g., local field potentials, for closed-loop neurostimulators to provide intelligent DBS therapies (Stanslaski et al., 2009).

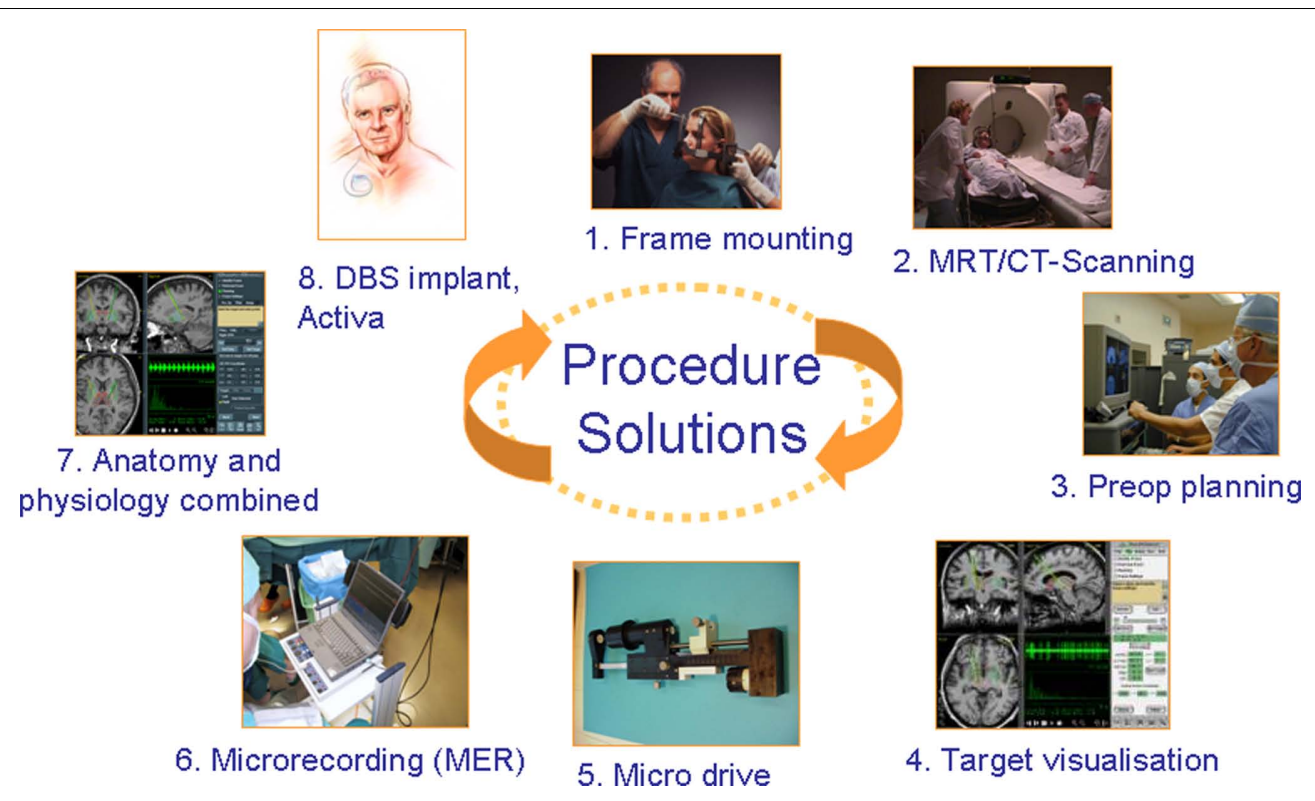

FIGURE 2 | Deep Brain Stimulator requires an multidisciplinary expert team and is a multi-step procedure involving stereotactic frame mounting (or "frameless" tools fixation); imaging, neurophysiological assessment, target verification prior to the DBS lead, and DBS system implantation. 


\section{CONCLUSION}

Deep Brain Stimulation is a novel technique which has shown beneficial results in individual patients in several central nervous system disorders including pain, movement disorders, psychiatric disorders, and epilepsy. DBS therapy and product development has depended on a close collaboration between industry and physician pioneers in the fields of interest. Today DBS for the treatment of essential tremor and the symptoms of PD is approved by the regulatory authorities in the US and Europe. DBS for the treatment of dystonia, and OCD is CE Mark approved in Europe and through the HDE process in the US. DBS for the treatment of epilepsy is approved in Europe but remains unapproved in the US.

The nervous system plays a role in the control of every body function and, as a result, it is tempting to think that DBS could

\section{REFERENCES}

Aouizerate, B., Cuny, E., Bardinet, E., Yelnik, J., Martin-Guehl, C., Rotge, J. Y., Rougier, A., Bioulac, B., Tignol, J., Mallet, L., Burbaud, P., and Guehl, D. (2009). Distinct striatal targets in treating obsessive-compulsive disorder and major depression. J. Neurosurg. 111, 775-779.

Benabid, A. L., Pollak, P., Gervason, C., Hoffmann, D., Gao, D. M., Hommel, M., Perret, J. E., and de Rougemont, J. (1991). Long-term suppression of tremor by chronic stimulation of the ventral intermediate thalamic nucleus. Lancet 337, 403-406.

Benabid, A. L., Pollak, P., Louveau, A., Henry, S., and de Rougement, J. (1987). Combined (thalamotomy and stimulation) stereotactic surgery of the VIM thalamic nucleus for bilateral Parkinson disease. Appl. Neurophysiol. 50, 344-346.

Benabid, A. L., Pollak, P., Seigneuret, E., Hoffmann, D., Gay, E., and Perret, J. (1993). Chronic VIM thalamic stimulation in Parkinson's disease, essential tremor and extra-pyramidal dyskinesias. Acta Neurochir. Suppl. (Wien) 58, 39-44.

Bewernick, B. H., Hurlemann, R., Matusch, A., Kayser, S., Grubert, C., Hadrysiewicz, B., Axmacher, N., Lemke, M., Cooper-Mahkorn, D., Cohen, M. X., Brockmann, H., Lenartz, D., Sturm, V., and Schlaepfer, T. E. (2010). Nucleus accumbens deep brain stimulation decreases ratings of depression and anxiety in treatmentresistant depression. Biol. Psychiatry 67, 110-116.

Boon, P., Vonck, K., De Herdt, V., Van Dycke, A., Goethals, M., Goossens, L., Van Zandijcke, M., De Smedt, T.,
Dewaele, I., Achten, R., Wadman, W., Dewaele, F., Caemaert, J., and Van Roost, D. (2007). Deep brain stimulation in patients with refractory temporal lobe epilepsy. Epilepsia 48, 1551-1560.

Brontë-Stewart, H., Louie, S., Batya, S., and Henderson, J. M. (2010). Clinical motor outcome of bilateral subthalamic nucleus deep-brain stimulation for Parkinson's disease using image-guided frameless stereotaxy. Neurosurgery 67, 1088-1093.

Coenen, V. A., Schlaepfer, T. E., Maedler, B., and Panksepp, J. (2010). Cross-species affective functions of the medial forebrain bundleImplications for the treatment of affective pain and depression in humans. Neurosci. Biobehav. Rev. doi: $\quad$ 10.1016/j.neubiorev.2010.12. 009. [Epub ahead of print].

Coubes, P., Roubertie, A., Vayssiere, N., Hemm, S., and Echenne, B. (2000). Treatment of DYT1-generalised dystonia by stimulation of the internal globus pallidus. Lancet 355 2220-2221.

Denys, D., Mantione, M., Figee, M., van den Munckhof, P., Koerselman, F., Westenberg, H., Bosch, A., and Schuurman, R. (2010). Deep brain stimulation of the nucleus accumbens for treatmentrefractory obsessive-compulsive disorder. Arch. Gen. Psychiatry 67, 1061-1068.

Deuschl, G., Schade-Brittinger, C., Krack, P., Volkmann, J., Schäfer, H., Bötzel, K., Daniels, C., Deutschländer, A., Dillmann, U., Eisner, W., Gruber, D., Hamel, W., Herzog, J., Hilker, R., Klebe, S., Kloss, M., Koy, J., Krause, M., Kupsch, A., Lorenz, D., Lorenzl, S., Mehdorn, H. M., Moringlane, J. R., Oertel, W., Pinsker, M. O., Reichmann, H., Reuss, A., Schneider, G.-H., Schnitzler, A., Steude, U.,

play a role in all medical dysfunction. Industry and physicians must be careful to select those potential applications of DBS that will bring maximum value to patients and must be committed to fully respect and comply with all applicable rules and regulations in the therapy development process and particularly in the conduct of clinical studies.

\section{DISCLAIMER}

The reader will note that the authors are associated with Medtronic, Inc. as employe and consultant. This paper contains information which discusses uses of DBS that have not been approved by regulatory agencies. Medtronic does not market its products for unapproved indications and can make no representations regarding the safety and/or efficacy of the devices if used for unapproved claims.

Sturm, V., Timmermann, L., Tronnier, V., Trottenberg, T., Wojtecki, L., Wolf, E., Poewe, W., Voges, J., and German Parkinson Study Group, Neurostimulation Section. (2006). A randomized trial of deepbrain stimulation for Parkinson's disease. N. Engl. J. Med. 355, 896-908.

Fisher, R., Salanova, V., Witt, T., Worth, R., Henry, T., Gross, R., Oommen, K., Osorio, I., Nazzaro, J., Labar, D. Kaplitt, M., Sperling, M., Sandok, E., Neal, J., Handforth, A., Stern, J., DeSalles, A., Chung, S., Shetter, A., Bergen, D., Bakay, R., Henderson, J., French, J., Baltuch, G., Rosenfeld, W. Youkilis, A., Marks, W., Garcia, P. Barbaro, N., Fountain, N., Bazil, C., Goodman, R., McKhann, G., Babu Krishnamurthy, K., Papavassiliou, S., Epstein, C., Pollard, J., Tonder, L., Grebin, J., Coffey, R., Graves, N., and SANTE Study Group. (2010). Electrical stimulation of the anterior nucleus of thalamus for treatment of refractory epilepsy. Epilepsia 51, 899-908.

Greenberg, B. D., Gabriels, L. A., Malone, D. A. Jr., Rezai, A. R., Friehs, G. M., Okun, M. S., Shapira, N. A., Foote, K. D., Cosyns, P. R., Kubu, C. S., Malloy, P. F., Salloway, S. P., Giftakis, J. E., Rise, M. T., Machado, A. G., Baker, K. B., Stypulkowski, P. H., Goodman, W. K., Rasmussen, S. A., and Nuttin, B. J. (2010). Deep brain stimulation of the ventral internal capsule/ventral striatum for obsessive-compulsive disorder: worldwide experience. Mol. Psychiatry 15 64-79.

Gruber, D., Trottenberg, T., Kivi, A., Schoenecker, T., Kopp, U. A., Hoffmann, K. T., Schneider, G. H., Kühn, A. A., and Kupsch, A. (2009). Long term effects of pallidal deep brain stimulation in tardive dystonia. Neurology 73, 53-58.

Haberler, C., Alesch, F., Mazal, P. R., Pilz P., Jellinger, K., Pinter, M. M., Hainfellner, J. A., and Budka, H. (2000). No tissue damage by chronic deep brain stimulation in Parkinson's disease. Ann. Neurol. 48, 372-376.

Halpern, C. H., Wolf, J. A., Bale, T. L., Stunkard, A. J., Danish, S. F., Grossman, M., Jaggi, J. L., Grady, M. S., and Baltuch, G. H. (2008). Deep brain stimulation in the treatment of obesity. J. Neurosurg. 109, 625-634.

Hamani, C., Mayberg, H., Stone, S., Laxton, A., Haber, S., and Lozano, A M. (2011). The subcallosal cingulate gyrus in the context of major depression. Biol. Psychiatry 15, 301-308.

Hariz, M. I., and Robertson, M. M. (2010). Gilles de la Tourette syndrome and deep brain stimulation. Eur. J. Neurosci. 32, 1128-1134.

Hodaie, M., Wennberg, R. A., Dostrovsky, J. O., and Lozano, A. M. (2002). Chronic anterior thalamus stimulation for intractable epilepsy. Epilepsia 43, 603-608.

Hosobuchi, Y., Adams, J. E., and Rutkin, B. (1973). Chronic thalamic stimulation for the control of facial anesthesia dolorosa. Arch. Neurol. 29, 158-161.

Krauss, J. K., Pohle, T., Weber, S., Ozdoba, C., and Burgunder, J. M. (1999). Bilateral stimulation of globus pallidus internus for treatment of cervical dystonia. Lancet 354, 837-838.

Kringelbach, M. L., and Aziz, T. Z. (2009). Deep brain stimulation: avoiding the errors of psychosurgery. JAMA 301, 1705-1707.

Kringelbach, M. L., Jenkinson, N., Owen, S. L. F., and Aziz, T. Z. (2007). Translational principles of deep brain stimulation. Nat. Rev Neurosci. 8, 623-635. 
Kupsch, A., Benecke, P., Müller, J., Trottenberg, T., Schneider, G.-H., Poewe, W., Eisner, W., Wolters, A., Müller, J.U., Deuschl, G., Pinsker, M. O., Skogseid, I. M., Roeste, G. K., VollmerHaase, J., Brentrup, A., Krause, M., Tronnier, V., Schnitzler, A., Voges, J., Nikkah, G., Vesper, J., Naumann, M., Volkmann, J., and Deep-Brain Stimulation for Dystonia Study Group. (2006). Pallidal deep-brain stimulation in primary generalized or segmental dystonia. N. Eng. J. Med. 355, 1978-1990.

Limousin, P., Pollak, P., Benazzouz, A., Hoffmann, D., Le Bas, J. F., Broussolle, E., Perret, J. E., and Benabid, A. L. (1995). Effect of Parkinsonian signs and symptoms of bilateral subthalamic nucleus stimulation. Lancet 14, 91-95.

Limousin, P., Speelman, J. D., Gielen, F., and Janssens, M. (1999). Multicenter European study of thalamic stimulation in Parkinsonism and essential tremor. J. Neurol. Neurosurg. Psychiatr. 66, 289-296.

Lipsman, N., Bernstein, M., and Lozano, A. M. (2010). Criteria for the ethical conduct of psychiatric neurosurgery clinical trials. Neurosurg. Focus 29, E9.

Mallet, L., Polosan, M., Jaafari, N., Baup, N., Welter, M. L., Fontaine, D., du Montcel, S. T., Yelnik, J., Chéreau, I., Arbus, C., Raoul, S., Aouizerate, B., Damier, P., Chabardès, S., Czernecki, V., Ardouin, C., Krebs, M. O., Bardinet, E., Chaynes, P., Burbaud, P., Cornu, P., Derost, P., Bougerol, T., Bataille, B., Mattei, V., Dormont, D., Devaux, B., Vérin, M., Houeto, J. L., Pollak, P., Benabid, A. L., Agid, Y., Krack, P., Millet, B., Pelissolo, A., and STOC Study Group. (2008). Subthalamic nucleus stimulation in severe obsessive-compulsive disorder. N. Engl. J. Med. 359, 2121-2134.

Malone, D. A. Jr., Dougherty, D. D., Rezai, A. R., Carpenter, L. L., Friehs, G. M., Eskandar, E. N., Rauch, S. L., Rasmussen, S. A., Machado, A. G., Kubu, C. S., Tyrka, A. R., Price, L. H., Stypulkowski, P. H., Giftakis, J. E., Rise, M. T., Malloy, P. F., Salloway, S. P., and Greenberg, B. D. (2009). Deep brain stimulation of the ventral capsule/ventral striatum for treatmentresistant depression. Biol. Psychiatry 65, 267-275.

Mayberg, H. S., Lozano, A. M., Voon, V., McNeely, H. E., Seminowicz, D., Hamani, C., Schwalb, J. M., and Kennedy, S. H. (2005). Deep brain stimulation for treatment-resistant depression. Neuron 45, 651-660.
Mueller, J., Skogseid, I. M., Benecke, R., Kupsch, A., Trottenberg, T., Poewe, W., Schneider, G. H., Eisner, W., Wolters, A., Müller, J. U., Deuschl, G., Pinsker, M. O., Roeste G. K., Vollmer-Haase, J., Brentrup, A., Krause, M., Tronnier, V., Schnitzler, A., Voges, J., Nikkhah, G., Vesper, J., Naumann, M., Volkmann, J., and Deep-Brain Stimulation for Dystonia Study Group. (2008). Pallidal deep brain stimulation improves quality of life in segmental and generalized dystonia: results from a prospective, randomized, shamcontrolled trial. Mov. Disord. 23, 131-134.

Nuttin, B., Cosyns, P., Demeulemeester, H., Gybels, J., and Meyerson, B. (1999). Electrical stimulation in anterior limbs of internal capsules in patients with obsessive-compulsive disorder. Lancet 354, 1526.

Owen, S. L., Green, A. L., Nandi, D. D. Bittar, R. G., Wang, S., and Aziz, T. Z. (2007). Deep brain stimulation for neuropathic pain. Acta Neurochir. Suppl. 97, 111-116.

Porta, M., Brambilla, A., Cavanna, A. E., Servello, D., Sassi, M., Rickards, H., and Robertson, M. M. (2009). Thalamic deep brain stimulation for treatment-refractory Tourette syndrome: two-year outcome. Neurology 73, 1375-1380.

Sartorius, A., Kiening, K. L., Kirsch, P., von Gall, C. C., Haberkorn, U., Unterberg, A. W., Henn, F. A., and Meyer-Lindenberg, A. (2010) Remission of major depression under deep brain stimulation of the lateral habenula in a therapy refractory patient. Biol. Psychiatry 67, e9-e11.

Siegfried, J., and Lippitz, B. (1994). Chronic electrical stimulation of the VL-VPL complex and of the pallidum in the treatment of movement disorders: personal experience since 1982. Stereotact. Funct. Neurosurg. $62,71-75$

Siegfried, J., and Shulman, J. (1987). Deep brain stimulation. Pacing Clin. Electrophysiol. 10, 271-272.

Stanslaski, S., Cong, P., Carlson, D., Santa, W., Jensen, R., Molnar, G. Marks, W. J. Jr., Shafquat, A., and Denison, T. (2009). An implantable bi-directional brain-machine interface system for chronic neuroprosthesis research. Conf. Proc. IEEE Eng. Med. Biol. Soc. 2009, 5494-5497.

Sturm, V., Lenartz, D., Koulousakis, A., Treuer, H., Herholz, K., Klein, J. C., and Klosterkötter, J. (2003). The nucleus accumbens: a target for deep brain stimulation in obsessive-compulsive- and anxietydisorders. J. Chem. Neuroanat. 26 293-299.

Temel, Y., and Visser-Vandewalle, V. (2004). Surgery in Tourette syndrome. Mov. Disord. 19, 3-14.

Testerman, R. L., Rise, M. T., and Stypulkowski, P. H. (2006). Electrical stimulation as a therapy for neurological disorder. IEEE Eng. Med. Biol. Mag. 25, 74-78.

The Deep Brain Stimulation for Parkinson's Disease Study Group. (2001) Deep brain stimulation of the subthalamic nucleus or the pars interna of the globus pallidus in Parkinson's Disease. N. Engl. J. Med. 345 956-963.

Trottenberg, T., Paul, G., Meissner, W. Maier-Hauff, K., Taschner, C., and Kupsch, A. (2001). Pallidal and thalamic neurostimulation in severe tardive dystonia. J. Neurol. Neurosurg. Psychiatry 70, 557-559.

Velasco, F., Velasco, M., Ogarrio, C. and Fanghanel, G. (1987). Electrical stimulation of the centromedian thalamic nucleus in the treatment of convulsive seizures: a preliminary report. Epilepsia 28, 421-430.

Vidailhet, M., Yelnik, J., Lagrange, C. Fraix, V., Grabli, D., Thobois, S., Burbaud, P., Welter, M. L., Xie-Brustolin, J., Braga, M. C., Ardouin, C., Czernecki, V., Klinger, H., Chabardes, S. Seigneuret, E., Mertens, P., Cuny, E., Navarro, S., Cornu, P., Benabid, A. L., Le Bas, J. F., Dormont, D. Hermier, M., Dujardin, K., Blond S., Krystkowiak, P., Destée, A. Bardinet, E., Agid, Y., Krack, P., Broussolle, E., Pollak, P., and French SPIDY-2 Study Group. (2009). Bilateral pallidal deep brain stimulation for the treatment of patients with dystonia-choreoathetosis cerebral palsy: a prospective pilot study. Lancet Neurol. 8, 709-717.

Voges, J., Hilker, R., Bötzel, K., Kiening, K. L., Kloss, M., Kupsch, A., Schnitzler, A., Schneider, G. H., Steude, U., Deuschl, G., and Pinsker, $M$ O. (2007). Thirty days complication rate following surgery performed for deep-brain-stimulation. Mov. Disord. 22, 1486-1489.

Vonck, K., Boon, P., Achten, E. De Reuck, J., and Caemaert, J. (2002). Long-term amygdalohippocampal stimulation for refractory temporal lobe epilepsy. Ann. Neurol. 52, 556-565.

Weaver, F. M., Follett, K., Stern, M., Hur, K., Harris, C., Marks, W. J. Jr., Rothlind, J., Sagher, O., Reda, D., Moy, C. S., Pahwa, R., Burchiel,
K., Hogarth, P., Lai, E. C., Duda, J. E., Holloway, K., Samii, A. Horn, S., Bronstein, J., Stoner, G., Heemskerk, J., Huang, G. D., and CSP 468 Study Group. (2009). Bilateral deep brain stimulation vs best medical therapy for patients with advanced Parkinson disease: a randomized controlled trial. JAMA 301, 63-73.

Williams, A., Gill, S., Varma, T., Jenkinson, C., Quinn, N., Mitchell, R., Scott, R., Ives, N., Rick, C., Daniels, J., Patel, S., Wheatley, K., and PD SURG Collaborative Group. (2010). Deep brain stimulation plus best medical therapy versus best medical therapy alone for advanced Parkinson's disease (PD SURG trial): a randomised, open-label trial. Lancet Neurol. 9, 581-591.

Witt, K., Daniels, C., Reiff, J., Krack, P., Volkmann, J., Pinsker, M. O., Krause, M., Tronnier, V., Kloss, M. Schnitzler, A., Wojtecki, L., Bötzel, K., Danek, A., Hilker, R., Sturm, V., Kupsch, A., Karner, E., and Deuschl, G. (2008). Neuropsychological and psychiatric changes after deep brain stimulation for Parkinson's disease: a randomized, multicentre study. Lancet Neurol. 7, 605-614.

Wojtecki, L., Vesper, J., and Schnitzler, A. (2011). Interleaving programming of subthalamic deep brain stimulation to reduce side effects with good motor outcome in a patient with Parkinson's disease. Parkinsonism Relat. Disord. 17, 293-294.

Conflict of Interest Statement: The authors are affiliated with Medtronic, Inc. as employee (Ali Sarem-Aslani) and consultant (Keith Mullett). Medtronic is a manufacturer of Deep Brain Stimulation systems.

Received: 23 February 2011; paper pending published: 20 May 2011; accepted: 16 August 2011; published online: 27 September 2011.

Citation: Sarem-Aslani $A$ and Mul lett $K$ (2011) Industrial perspective on deep brain stimulation: history, current state, and future developments. Front. Integr. Neurosci. 5:46. doi: 10.3389/fnint.2011.00046

Copyright (c) 2011 Sarem-Aslani and Mullett. This is an open-access article subject to a non-exclusive license between the authors and Frontiers Media $S A$, which permits use, distribution and reproduction in other forums, provided the original authors and source are credited and other Frontiers conditions are complied with. 